\title{
NAUFRÁGIOS DO IMPÉRIO: POÉTICAS DE UM MAR NÃO MAIS PORTUGUÊS
}

Paulo Motta Oliveira

Universidade de São Paulo

Levando a bordo El-Rei D. Sebastião,

E erguendo, como um nome, alto o pendão

Do Império,

Foi-se a última nau, ao sol aziago

Erma, e entre choros de ânsia e de presago

Mistério.

Não voltou mais.

A

ssim inicia Fernando Pessoa (1983, p.16) o penúltimo poema de Mar Português. Ao transformar em última nau aquela que levou o malfadado reimenino para as areias de Alcácer Quibir, Pessoa apaga mais de três séculos da história de seu país. Está aqui a seguir os passos do História de Portugal de Oliveira Martins, em que o polígrafo autor considerou que a nação havia morrido quando findou a sua segunda dinastia. "Nesse túmulo que encerrava, com os cadáveres do poeta e do rei, o da Nação, havia dois epitáfios: um foi o sonho sebastianista; o outro foi, é, o poema d'Os Lusíadas. A pátria fugira da terra para a região aérea da poesia e dos mitos" (MARTINS, s.d., v.2, 57).

Será novamente, bem o sabemos, com a poesia e com o mito que o poeta de Mensagem tentará reencontrar um sentido para o seu país-nevoeiro, transformando-o em espaço propício para o advento desse Galaaz com pátria que poderá, finalmente, passados os quatro tempos do ser que sonhou, revelar ao mundo dividido o Santo Graal. Mas para entendermos por que esse país transformou-se em nevoeiro, precisamos justamente visitar os três séculos apagados por Pessoa e Martins, aqueles mesmos séculos que Antero de Quental amargamente analisou na sua segunda conferência na Sala do Casino 
Lisbonense (cf. QUENTAL, 1982, p.255-296), e neles encontrar uma outra morte que transformará o Portugal oitocentista no espaço de total desesperança descrito no terrível "Inscrição" de Camilo Pessanha (1995, p.75):

Eu vi a luz em um país perdido.

A minha alma é lânguida e inerme.

Oh! Quem pudesse deslizar sem ruído!

No chão sumir-se, como faz um verme...

Portugal não morreu nas areias de Alcácer. Lá ficou apenas o seu ser que houve, multicontinental império sustentado pelas especiarias da Índia e pelas praças de África. Quando ressurgiu, sessenta anos depois da morte do cardeal D. Henrique, livrando-se do jugo de Espanha, já era um novo ser, já teria, para usarmos uma genial metáfora de Eduardo Lourenço (1978), recoberto o seu frágil corpo com a pela americana. O Portugal dos séculos XVII e XVIII teve o Brasil como seu coração: a cana de açúcar primeiro, o ouro depois, o pacto colonial sempre, estes foram os sustentáculos que permitiram a sobrevivência do império português.

Mas toda a história tem um fim. E uma outra nau, saída às pressas de Lisboa, seria a última. A bordo, não o rei-menino, mas uma corte que fugia atabalhoada das tropas de Napoleão, que já estavam às portas da cidade. Foi esta a nau que levou o pendão do império. E não voltou mais. Quando, quatorze anos depois, D. João VI retornar para Portugal, convertido no primeiro rei constitucional do país, terá deixado para trás um Brasil que não mais será colônia, mas parte do reino unido. E, poucos anos depois, o herdeiro da coroa, D. Pedro, irá proclamar a independência do território americano.

Podemos pensar que o século XIX, século também longo para Portugal, mas por motivos diversos daqueles apontados por Hobsbawm (1997, 1998, 2000) para os países centrais da Europa, foi o réquiem por um corpo insepulto em lenta decomposiçóo. Ou, talvez ainda melhor, foi a narrativa construída por um coro de desesperados sobre um naufrágio que parecia jamais ter fim. João Medina com muita acuidade notou:

A obsessão da decadência nacional, dum progressivo e inelutável declínio de todo o País, complexo de morbos, reações, profecias e desesperos que 
podíamos resumir na expressão de miséria portuguesa, atravessa todas as grandes obras literárias da segunda metade do séc. XIX português, embora se fizesse sentir, velada, surda mas às vezes lúcida e consciente, na primeira metade da centúria, por exemplo, num Garrett ou num Herculano, cujos espíritos, aqui e além, se deixam avassalar pelo sentimento dum ocaso da grei sobre a qual pesavam prenúncios de catástrofe. (MEDINA, 1974, p.33-35)

O século XIX, que consideramos que só chega de fato a terminar quando as possessões africanas se transformam em verdadeiro espaço colonial, ou seja, em torno da década de 20 do século passado, foi a incessante busca de uma resposta para essa estreita faixa de terra espremida entre a Europa e o Atlântico, país que não podia enxergar a sua própria pequenez, que necessitava de novas peles para recobrir seus frágeis ossos. Esta nação, habituada a ser, como bem o notou Boaventura Santos (1997), a periferia da Europa e o centro de suas colônias, se viu transformada, durante um século, apenas em periferia, em um reino à esquina do planeta, como magistralmente sintetizou António Nobre.

Rastrear as poéticas desse mar que não mais é português é mapear um espaço que foi vedado ao país, ao mesmo tempo objeto do desejo e fruto inalcançável. Quando Garrett, no início da segunda metade da centúria reescreve a epopéia camoniana nesse poema magistral que é "Cascais”, está a mostrar que a aventura coletiva não mais é possível. "Acabava ali a Terra”, "Lá onde se acaba a Terra!", "Inda ali acaba a Terra” (GARRETT, 1963, v.2, p.1957). Esta mesma idéia, repetida em três versos distintos, no início, no meio e no fim do poema, remetem-nos diretamente para a forma como, em Os lusíadas (1982, p.82), Vasco da Gama descreve a posição geográfica de seu país:

Eis aqui, quase no cume da cabeça

De Europa toda, o reino lusitano,

Onde a terra se acaba e o mar começa

E onde Febo repousa no oceano

A referência à mais importante epopéia portuguesa ocorre em um poema que, devemos notar, não deixa de ter seu caráter épico. Como em toda a épica o eu lírico do poema alcança, no fim de sua jornada, um nível de conhe- 
cimento superior ao que tinha quando a iniciou. Além disso, se em Os lusíadas os portugueses eram os escolhidos por Deus para espalhar pelo mundo a fé cristã, também em "Cascais" (GARRET, 1963, v.2, p.196), o amante pertence a uma categoria de eleitos:

Os anjos aqueles dias

Contaram na eternidade:

Que essas horas fugidias,

Séculos na intensidade,

Por milênios marca Deus

Quando as dá aos que são seus.

Mas a odisséia, construída no poema, nada tem de coletiva. Foi uma experiência pessoal, pela qual o eu passou, em um espaço isolado, junto com sua amada (GARRETT, idem):

Ali sós no mundo, sós

Santo Deus! , como vivemos!

Como éramos tudo nós

E de nada mais soubemos!

Como nos folgava a vida

De tudo o mais esquecida!

A ausência do coletivo, em um poema que tem Os lusíadas como um de seus intertextos, parece indicar que, para esse último Garrett, apenas individualmente pode-se chegar a uma lha dos Amores. O país, que tão amorosamente tentara regenerar, com seu braço às armas feito, com sua mente às musas dada, está aqui ausente, e apenas fornece um substrato cultural que permite ao eu construir a sua epopéia solitária.

Mas ainda aqui existe um navegar possível, uma experiência que pode ser vivida. Quase trinta anos depois parece que até mesmo esta saída individual está vedada. Estamos aqui a pensar em $O$ sentimento de um ocidental e na imagem de uma Lisboa que só pode provocar sensações de clausura e confinamento. "Semelham-se a gaiolas, com viveiros, / As edificações somente emadeiradas" (Verde: 1983, p.89). As varinas "apinham-se num bairro aonde miam gatas, / E o peixe podre gera os focos de infecção" (idem, 
p.91), “A noite pesa, esmaga” (idem, p.93). Nesse espaço sufocante, o eu lírico afirma: "E eu sonho o Cólera, imagino a Febre, / Nessa acumulação de corpos enfezados" (idem, p.92).

Essa cidade pesadelo não é gerada apenas por aquilo o eu lírico objetivamente observa. A caminhada desse flaneur é também um percurso pelas marcas e restos do passado, por tudo aquilo que, tendo existido outrora, ainda está de alguma forma presente - enquanto memória, espaço de ausência ou permanência efetiva - nas ruas e vielas dessa urbe escura, soturna e melancólica. Aquilo que, outrora, foi de alguma forma positivo, não mais existe. Assim, por exemplo, a visão dos "cais a que se atracam botes" faz com que o eu lírico evoque "as crônicas navais: / Mouros, baixeis, heróis, tudo ressuscitado! / Luta Camões no Sul, salvando um livro a nado! / Singram soberbas naus que eu não verei jamais!" (idem, p.90). A oposição entre as naus do passado e os botes do presente vai ecoar ainda nas estrofes subseqüentes: o poeta notará a presença de um "couraçado inglês”, marca inegável de que o mar, agora, não mais é português; verá, como apontou Helder Macedo (1975), no lugar dos barões assinalados um "cardume negro" de "hercúleas" e "galhofeiras" varinas, algumas das quais "à cabeça, embalam nas canastras / Os filhos que depois naufragam nas tormentas" (idem, p.90).

O próprio Camões foi convertido apenas em sinal, ineficaz, de sua existência passada: “(...) num recinto público e vulgar, / Com bancos de namoro e exíguas pimenteiras, / Brônzeo, monumental, de proporções guerreiras, / Um épico doutrora ascende, num pilar! “ (idem, p.92).

Ao lado desses despojos do que de positivo houve, tudo aquilo que existiu de negativo, de opressor, ou se mantém, ou se modifica apenas para, de outra forma, ser imperecível. O "ermo inquisidor severo" é recordado pela "nódoa negra e fúnebre do clero” (idem, p.92) que, no presente, ainda existe. Os conventos modificaram-se, mas permanece seu papel de confinamento, pois "Partem patrulhas de cavalaria / Dos arcos dos quartéis que já foram conventos” (idem, p.92). "As burguesinhas do Catolicismo" lembram "ao chorar dolente dos pianos, / As freiras que os jejuns matavam de histerismo” (idem, p.93).

Esse duplo passeio, pela cidade presente e pelos restos do passado, mostra um dado interessante: o que de positivo houve, e desapareceu no 
presente, foi o navegar, do qual só sobraram restos degradados. Já a religião, com sua sombra que equivale à da cidade, continua viva e presente, seja enquanto tal, seja transmutada em outros significantes, que remetem ao mesmo significado. A prisão - religiosa ou laica - mantém as suas grades.

Nesse poema urbano e sufocante, não existem mais saídas, mesmo que individuais. Mas ainda é possível o delírio. Em um momento o eu escuta "no silêncio, infaustas e trinadas, / As notas pastoris de uma longýnqua flauta" (idem, p.96) . Será o som dessa agreste avena ou frauta ruda que fará com que o eu lírico, superando a pequenez presente, a prisão escura de sua cidade labiríntica, erga em fúria grande e sonorosa o seu delírio que, devemos notar, nada tem de belicoso. Se é o passado das navegações que recupera, o que delas retém é o mar sem praias, a cidade sem paredes, a vida sem fim (idem, p.96):

Se eu não morresse nunca! E eternamente

Buscasse e conseguisse a perfeição das cousas!

Esqueço-me a prever castíssimas esposas,

Que aninhem em mansões de vidro transparente!

Ó nossos filhos! Que de sonhos ágeis,

Pousando, vos trarão a nitidez às vidas!

Eu quero as vossas mães e irmãs estremecidas,

Numas habitações translúcidas e frágeis.

Ah! Como a raça ruiva do porvir,

E a frota dos avós, e os nómadas ardentes,

Nós vamos explorar todos os continentes

E pelas vastidões aquáticas seguir!

Mas esta aparente recuperação da mobilidade passada, que instaura um tempo em que os muros que sufocam se transformam em mansões de vidro, em que a cidade prisão é trocada pela vastidão aquática de um mar sem praias, é destruída pelo peso do presente. $\mathrm{O}$ eu lírico, e os outros citadinos, descendentes daqueles avós de um passado já remoto, estão “emparedados, / Sem árvores, no vale escuro das muralhas!...” (idem, p.96). O poema termina, como havia iniciado, pela dor, em que o próprio mar, 
espaço aberto por excelência, transforma-se: "A Dor humana busca amplos horizontes, / E tem marés, de fel, como um sinistro mar!" (idem, p.97).

A raça dos avós está em um passado irrecuperável para este tempo em que o mar não mais não mais é português. Todo a magia se perdeu. É inevitável, aqui, voltarmos ao poema de Nobre a que já nos referimos, que quase na mesma época do de Cesário transformará em fado individual esta experiência de fracasso que, como bem podemos notar, é coletiva:

Em certo reino, à esquina do Planeta,

Onde nasceram meus Avós, meus Pais,

Há quatro lustros, viu a luz um poeta

Que melhor fora não a ver jamais.

Mal despontava para a vida inquieta,

Logo ao nascer, mataram-lhe os ideais,

À falsa fé, numa traição abjecta,

Como os bandidos nas estradas reais!

E, embora eu seja descendente, um ramo

Dessa árvore de Heróis que, entre perigos

E guerras, se esforçaram pelo Ideal:

Nada me importas, País! seja meu Amo

O Carlos ou o Zé da T'resa...Amigos,

Que desgraça nascer em Portugal!

(NOBRE, 1979, p.148)

O tom infantil, o vocabulário de contos de fadas, tudo reenvia para a falta de magia do presente. Nada mais aqui parece existir. Estamos a um passo do Portugal nevoeiro de Pessoa. É uma desgraça nascer neste espaço de que toda a heroicidade foi retirada, em que parece existir só uma apagada e vil tristeza. Como diria em tom sarcástico Álvaro de Campos, "Pertenço a um gênero de portugueses/Que depois de estar a Índia descoberta/Ficaram sem trabalho. A morte é certa/Tenho pensado nisto muitas vezes" (PESSOA, 1982, p.238).

Também a morte do país era certa, mas sempre adiada.

Eduardo Lourenço uma vez notou que "Antero [de Quental] é a primeira consciência portuguesa separada de si mesma, irremediavelmente dual" (LOURENÇO, 1978, p.99). Podemos pensar que toda a experiência portuguesa nesse infindável e dilacerante século XIX é irremediavelmente 
dual, pois é todo o país que está separado de si mesmo. Perdido o ser que houve, Portugal não sabe encontrar o ser que há. Está parado nessa imensa calmaria, tão bem apontada por Pessanha em "San Gabriel”, que parece não ter fim. Talvez a melhor imagem desta situação foi debuxada por Mário de Sá-Carneiro (1995, p.82), que, como Nobre, transformou em pessoal um destino que era coletivo:

Eu não sou eu nem sou o outro,

Sou qualquer coisa de intermédio:

Pilar da ponte de tédio

Que vai de mim para o Outro.

Garrett, Cesário, Nobre, Pessanha, Pessoa, Sá-Carneiro. Todos eles constroem uma poética de desalento, e são algumas das vozes que entoam esse cantar de lamentos que se torna cada vez mais pungente. Já notei (OLIVEIRA, 2002b) que estes mesmos escritores, junto a outros, também constroem, em outras obras, um canto de esperança, também eles antevêem, às vezes em momentos muito próximos aos que escrevem estes poemas, uma saída: el rei menino há de vir, como indicará Nobre, San Gabriel abençoará o mar, como esperará Pessanha, é a hora, como afirmará Pessoa. Talvez Antero, com a sua dualidade, possa mesmo ser considerado como a figura símbolo de todo este período.

Para encerrarmos estas breves anotações, em que coordenamos e desenvolvemos algumas idéias que já havíamos apresentado em outros momentos (OLIVEIRA, 1999, 2002a, 2002c), gostaria de citar o soneto "Portugal”, escrito pelo espanhol que melhor soube entender esta mistura de desalento e delírio que atravessa esse longo século XIX. Refiro-me, obviamente, a Miguel de Unamuno (1986, p..78):

Del Atlántico mar en las orillas desgreñada y descalza una matrona se sienta al pié de sierra que corona triste pinar. Apoya en las rodillas los codos y en las manos las mejillas y clava ansiosos ojos de leona en la puesta del sol. El mar entona 
su trágico cantar de maravillas.

Dice de luengas tierras y de azares

mientras ella sus piés en las espumas

bañando sueña en el fatal imperio

que se hundió en los tenebrosos mares,

y mira cómo entre agoreras brumas

se alza Don Sebastián, rey del misterio

Um claro sentido descensional percorre todo o poema, como percorreu todo o século. O mar, que em outro texto Unamuno (1985, p.148-149) considerou que é, para Portugal, um enorme cemitério de homens e de glórias, entoa o seu cantar de maravilhas enquanto o país, essa mulher desgrenhada e descalça, sonha com o fatal império que naufragou. Mas toda essa queda se opõe, no último verso, ao verbo alzar que é aplicado a D. Sebastião. Ele se levanta, vindo do mar, restituindo o país de sua queda. É este retorno que a mulher, com olhos de leoa, vê ao olhar o pôr do sol. Como diria Pessoa, cumpriu-se o mar e o império de desfez. Vários escritores oitocentistas tentaram acreditar, desesperadamente, que era chegada a hora de cumprir-se Portugal. Pouco mais aqui fizemos que a cartografia dos naufrágios dessa esperança.

\section{BIBLIOGRAFIA}

CAMÕES, Luís de. Os lusíadas. São Paulo: Cultrix, 1982.

GARRETT, Almeida. Obras. Porto: Lello \& Irmão, 1963, v.2.

HOBSBAWM, Eric J. A era das revoluções (1789-1848). São Paulo: Paz e Terra, 2000. HOBSBAWM, Eric J. de A era do capital (1848-1875). São Paulo: Paz e Terra, 1997. HOBSBAWM, Eric J. de $A$ era dos impérios (1875-1914). São Paulo: Paz e Terra, 1998. LOURENÇO, Eduardo. O labirinto da saudade. Lisboa: Dom Quixote, 1978. MACEDO, Helder. Nós Uma leitura de Cesário Verde.Lisboa: Plátano, 1975. MARTINS, Oliveira. História de Portugal. Lisboa: Europa-América, s.d. v.2. MEDINA, João. Eça político. Lisboa: Seara Nova, 1974.

NOBRE, António. Só. 18.ed. Porto: Livraria Tavares Martins, 1979.

OLIVEIRA, Paulo Motta Peles americanas em corpo europeu: o Brasil na literatura portuguesa oitocentista. Convergência Lusíada, Rio de Janeiro, v. 19, p. 364-376, 2002a. 
OLIVEIRA, Paulo Motta. Camões e Garrett: navegações do Restelo a Cascais. Scripta, Belo Horizonte, PUC Minas, v.3, n.5, p.173-186, 2º sem. 1999.

OLIVEIRA, Paulo Motta. De navegações e naufrágios: imagens de Portugal de Garrett a Pessoa. PEREIRA, Edgard; OLIVEIRA, Paulo Motta; OLIVEIRA, Silvana Maria Pessoa de. Intersecções Ensaios de Literatura Portuguesa. Campinas: Komedi, 2002b. p.69-162.

OLIVEIRA, Paulo Motta. Rotas de papel: de cidades e províncias. Semear, Rio de Janeiro, n.6, p.249-261, 2002c.

PESSANHA, Camilo. Clepsydra. Lisboa: Relógio D’Água, 1995

PESSOA, Fernando. Obra poética. Rio de Janeiro: Editora Nova Aguilar, 1983.

QUENTAL, Antero. Prosas sócio-politicas. Lisboa: Imprensa Nacional - Casa da Moeda, 1982.

SÁ-CARNEIRO, Mário. Obra Completa. Rio de Janeiro: Editora Nova Aguilar, 1995, p. 717-975.

SANTOS, Boaventura de Sousa. Pela mão de Alice. 6.ed. Porto: Afrontamento, 1997. UNAMUNO, Miguel de. Escritos de Unamuno sobre Portugal. Paris: Fundação Calouste Gulbenkian, 1985.

UNAMUNO, Miguel de. Portugal. PASCOAES, Teixeira de, UNAMUNO, Miguel de. Epistolário ibérico. Lisboa: Assírio e Alvin, 1986, p. 78.

VERDE, Cesário. Obra completa de Cesário Verde. Lisboa: Livros Horizonte, 1983. 